\title{
Stage IVA Oral Cavity Adenoid Cystic Carcinoma AJCC v6 and v7
}

National Cancer Institute

\section{Source}

National Cancer Institute. Stage IVA Oral Cavity Adenoid Cystic Carcinoma A/CC v6 and

v7. NCI Thesaurus. Code C5863.

Stage IVA includes: (T4a, N0, M0); (T4a, N1, M0); (T1, N2, M0); (T2, N2, M0); (T3, N2, M0); (T4a, N2, M0). T4a: Oral cavity cancer with moderately advanced local disease.

Tumor invades adjacent structures only (e.g., through cortical bone [mandible or maxilla] into deep [extrinsic] muscle of tongue [genioglossus, hyoglossus, palatoglossus, and styloglossus], maxillary sinus, skin of face). T1: T umor $2 \mathrm{~cm}$ or less in greatest dimension. T2: Tumor more than $2 \mathrm{~cm}$ but not more than $4 \mathrm{~cm}$ in greatest dimension. T3: T umor more than $4 \mathrm{~cm}$ in greatest dimension. N0: No regional lymph node metastasis. N1: Metastasis in a sing le ipsilateral lymph node, $3 \mathrm{~cm}$ or less in greatest dimension. N2: Metastasis in a single ipsilateral lymph node, more than $3 \mathrm{~cm}$ but not more than $6 \mathrm{~cm}$ in greatest dimension; or in multiple ipsilateral lymph nodes, none more than $6 \mathrm{~cm}$ in greatest dimension; or in bilateral or contralateral lymph nodes, none more than $6 \mathrm{~cm}$ in greatest dimension. M0: No distant metastasis. (AJCC 7th ed.) 